\title{
The Relationship Between Diabetic Retinopathy and Serum and 24-Hours Urine Mindin Levels in Patients with Type 2 Diabetes Mellitus
}

\section{Ibrahim Dogan}

Hitit University Faculty of Medicine: T C Hitit Universitesi Tip Fakultesi

Cagatay Caglar ( $\nabla$ doktorcagatay@gmail.com )

T C Hitit Universitesi Tip Fakultesi https://orcid.org/0000-0003-4391-2571

Ahmet Gursoy

Hitit University Faculty of Medicine: T C Hitit Universitesi Tip Fakultesi

Huseyin Kayadibi

Hitit University Faculty of Medicine: T C Hitit Universitesi Tip Fakultesi

\section{Research Article}

Keywords: Diabetes mellitus, Diabetic retinopathy, Mindin, Proteinuria.

Posted Date: February 8th, 2022

DOI: https://doi.org/10.21203/rs.3.rs-1332810/v1

License: (a) (i) This work is licensed under a Creative Commons Attribution 4.0 International License. Read Full License 


\section{Abstract}

Purpose: To investigate the 24-hours urine and serum mindin levels and the correlation with diabetic retinopathy (DR) severity.

Methods: Our study included 26 patients with Type 2 diabetes mellitus (DM) diagnosis without DR (Group 1), 25 patients with non-proliferative DR (Group 2), 25 patients with proliferative DR (Group 3) and 25 individuals as control group. Patients were compared in terms of serum and 24-hours urine mindin levels. Mindin measurements were performed by ELISA method.

Results: Serum mindin levels were identified to be statistically lower in Group 3 compared to Groups 1 and 2 ( $p<0.001, p=0.001$, respectively). There was a statistically significant difference between 24-hours mindin levels in the control group compared to Groups 1,2 and $3(p=0.046, p<0.001, p<0.001$, respectively). Correlation analyses identified a positive correlation between 24-hours urine mindin levels with severity of $\mathrm{DR}, \mathrm{HbA1c}$, proteinuria and insulin use. Multivariate logistic regression analysis identified that $\mathrm{HbA1c}$, urine mindin level and proteinuria were associated with DR. Serum mindin level was not found to be significant to predict for DR.

Conclusion: 24-hours urine mindin levels were identified to be higher in patients with DM compared to non-diabetic control group. Urine mindin levels were also found to increase in correlation with the severity of DR. This is the first study to investigate the relationship between DR, blood and 24-hour urine mindin level.

\section{Introduction}

Diabetic retinopathy (DR) is one of the primary reasons of preventable and treatable blindness globally [1]. With the increase in prevalence of diabetes mellitus (DM) and increased life expectancy of diabetic patients, the number of patients with DR are increasing day by day [2].

Histologic studies show loss of pericytes and endothelial cells in retinal capillary veins in early period DR [3]. Pericyte cell loss, acellular capillaries, microaneurysms and capillary base thickening are pathological causes of DR [4]. It is caused by pathological pathways similar to diabetic retinopathy and nephropathy. Damage to podocyte cells in the glomerular capillaries has been shown to play an important role in diabetic nephropathy (DN) [5]. A variety of studies have shown there is a close correlation between the incidence of diabetic retinopathy and nephropathy [6-7].

Local inflammation is accepted as an important risk factor for development and progression of DR and DN [8]. Mindin (Spondin-2) is a molecule with protein structure in the extracellular matrix family and it was identified to play a key role in the initiation of the immune response. It has a critical role in migration of inflammatory cells and is known to act as a ligand for integrins in in vitro environments [9]. Mindin is associated with podocyte injury and was shown to be a possible early marker of DN progression [10]. 
Encountering similar capillary cell injury and inflammation process in DN and DR pathogenesis brings to mind the idea that a range of similar molecules may be responsible for their pathogenesis. Mindin, a factor involved in initiation and progression of the inflammatory response in glomerular capillaries may cause damage in DR by similar mechanisms. Detection of such a molecule before clinically visible microvascular complications forms will be beneficial in terms of preventing damage caused by DR in early stage. In our study, we aimed to investigate whether the mindin molecule is an early indicator of DR and its relationship with DR severity. Therefore, we investigated the correlation between DR stages and 24-hour serum and blood mindin levels.

\section{Materials And Methods}

The study was prospectively completed at Hitit University Education and Research Hospital. It was approved by Ethics Committee of Hitit University Medicine Faculty (06.01.2017/2016.52). All patients provided written consent stating they accepted participation in the study

Patients with type 2 DM diagnosis for at least 6 months were included in the study. Those with acute complications linked to diabetes, who were morbidly obese, had active infection findings, had active malignancy, had acute coronary events in the last 6 weeks, those with decompensated chronic liver disease, with New York Heart Association class 3 and 4 heart failure, with surgical intervention in the last 1 month, with burns or severe trauma, with retina and vitreous surgery, with uveitis, trauma-linked situations, or accompanying retina diseases were not included in the study. The comorbid diseases and medications used were recorded in the study population. Smoking habits of those in the study population were noted. The arterial pressure (AP) values of patients were taken as the mean of 3 measurements taken on both arms. Body mass index (BMI) was calculated with the formula weight $(\mathrm{kg}) / \mathrm{height}\left(\mathrm{m}^{2}\right)$. Patients had dilated fundus examinations performed by retina specialist with fundus fluorescein angiography and optical coherence tomography performed if necessary. Patients with non-proliferative and proliferative diabetic retinopathy were classified according to the Early Treatment of Diabetic Retinopathy Study [12].

Patients were divided into 4 groups; 26 patients with type 2 DM diagnosis and no DR (55 \pm 9 years) (Group 1); 25 patients with non-proliferative DR (61 \pm 8 years) (Group 2); 25 patients with proliferative DR diagnosis ( $60 \pm 7$ years) (Group 3 ); and 25 people without DM diagnosis ( $53 \pm 11$ years) (control group). All patients had mindin, full blood count, glucose, blood urea nitrogen (BUN), creatinine, sodium ( $\mathrm{Na})$, potassium $(\mathrm{K})$, calcium $(\mathrm{Ca})$, phosphorus $(\mathrm{P})$, uric acid, total protein (T. Protein), albumin, total cholesterol (T. Cholesterol), low density lipoprotein cholesterol (LDL-c), high density lipoprotein cholesterol (HDL-C), triglyceride (TG), c-reactive protein (CRP), HbA1c and protein urea tests in 24-hours urine studied. Serum samples were collected from patients between 08:00-12:00 after 12 hours fasting. After coagulation, blood samples, they were centrifuged for 5 minutes at $4000 \mathrm{rpm}$ and serum was obtained. Urine was collected over 24 hours. Serum and urine samples for mindin measurements were stored at $-80^{\circ} \mathrm{C}$ until study with other biochemical test parameters studied on the same day. Biochemical blood parameters, 24-hours urine protein and creatinine tests were measured photometrically with standard measurement 
methods using commercial kits with an autoanalyzer. Full blood counts were completed using standard measurement methods with automated full blood count device. HbA1c analysis was performed using standard measurement methods. Serum and urine mindin values were measured with the ELISA method (Cat. No: YLA0860HU). The inter and intra assay CV values for the method were $<8 \%$ and $<10$, respectively, with measurement interval between $0.05 \mathrm{ng} / \mathrm{mL}$ and $38 \mathrm{ng} / \mathrm{mL}$ with sensitivity of 0.031 $\mathrm{ng} / \mathrm{mL}$. Measurements were performed using the EZ Read 400 ELISA microplate reader (Biochrom, UK).

Statistical analyses were performed with IBM SPSS Statistics version 23 program. Distribution of variables was analyzed with the Shapiro Wilk test. Parameters with normal distribution are given as mean \pm standard deviation, while parameters without normal distribution are shown as median (25\%-75\% quartiles). One-way ANOVA analysis and multiple comparison methods were used to compare groups with normal distribution. Kruskall Wallis variance analysis and Mann-Whitney $U$ test was used for comparison of groups without normal distribution. The chi-square test and Fisher exact test were used to compare categorical variables. Spearman correlation test was used for correlation analysis. Multivariate logistic regression analysis was used for prediction of groups with and without retinopathy. $P$ values $<0.05$ were accepted as statistically significant.

\section{Results}

The demographic data, body mass index (BMI), smoking habits, comorbid diseases and systemic medication use of the study population are given in Table 1. There were no statistical differences between the groups in terms of age (exclude between group 2 and control group), gender distribution, BMI, smoking habits, systolic blood pressure and diastolic blood pressure ( $p>0.05)$ (Table 1$)$. While there was no statistically significant difference between group 1 and group 2-3 in terms of oral antidiabetic use, insulin use was significantly higher in groups 2 and 3 compared to group 1. There was a significant difference between group 1 and group 2-3 in terms of hypertension and coronary artery disease. Coronary artery disease was statistically significantly higher in Group 2 (NPDRP) compared to Group 3 (PDRP). Considering the drug use, the use of Angiotensin-converting enzyme Inhibitors/Angiotensin receptor blockers and diuretics was statistically significantly higher in groups 2 and 3 . Statin use was statistically significantly higher in group 2 compared to group 3 . 
Table 1

The demographic characteristics, medications and co-morbidities of the studied population.

\begin{tabular}{|c|c|c|c|c|c|}
\hline & $\begin{array}{l}\text { Controls } \\
(n=25)\end{array}$ & $\begin{array}{l}\text { Group } 1 \\
(n=26)\end{array}$ & $\begin{array}{l}\text { Group } 2 \\
(n=25)\end{array}$ & $\begin{array}{l}\text { Group } 3 \\
(n=25)\end{array}$ & $P$ \\
\hline Age (years) & $53 \pm 11$ & $55 \pm 9$ & $61 \pm 8^{a}$ & $60 \pm 7$ & 0.006 \\
\hline Gender (F/M) & $(16 / 9)$ & $(16 / 10)$ & $(14 / 11)$ & $(16 / 9)$ & 0.930 \\
\hline \multirow[t]{2}{*}{$\mathrm{BMI}\left(\mathrm{kg} / \mathrm{m}^{2}\right)$} & 29.1 & 31.1 & 30.8 & 32.2 & \multirow[t]{2}{*}{0.065} \\
\hline & $(26.1-31.2)$ & (28.3-34.8) & $(28.2-34.9)$ & $(26.7-34.2)$ & \\
\hline Smoking & 4 & 4 & 2 & 3 & 0.914 \\
\hline SBP $(\mathrm{mm} \mathrm{Hg})$ & $126 \pm 15$ & $123 \pm 16$ & $127 \pm 17$ & $129 \pm 5$ & 0.598 \\
\hline $\mathrm{DBP}(\mathrm{mm} \mathrm{Hg})$ & $80 \pm 10$ & $76 \pm 12$ & $76 \pm 9$ & $78 \pm 9$ & 0.489 \\
\hline HT & 6 & 8 & 19 & 18 & $<0.001^{\star}$ \\
\hline CAD & 1 & 3 & 11 & 5 & $0.003^{\star}$ \\
\hline PAD & 1 & 1 & 0 & 1 & 1 \\
\hline CVD & 0 & 0 & 2 & 1 & 0.936 \\
\hline PD & 2 & 0 & 3 & 2 & 0.703 \\
\hline ACEi/ARB & 4 & 6 & 16 & 15 & $<0.001^{\star}$ \\
\hline Diuretics & 1 & 5 & 10 & 10 & $0.007 *$ \\
\hline CCB & 4 & 2 & 8 & 4 & 0.172 \\
\hline BB & 0 & 3 & 8 & 5 & 0.053 \\
\hline Statin & 0 & 4 & 9 & 1 & $0.005^{\star}$ \\
\hline ASA & 2 & 4 & 10 & 5 & $0.036^{*}$ \\
\hline Insulin** & 0 & 12 & 19 & 19 & $0.034^{\star}$ \\
\hline Thiazolidinediones** & 0 & 3 & 4 & 0 & 0.119 \\
\hline Biguanide** & 0 & 20 & 18 & 15 & 0.403 \\
\hline SU/Glinides** & 0 & 8 & 5 & 3 & 0.256 \\
\hline DPP-4 inhibitors** & 0 & 12 & 5 & 5 & 0.058 \\
\hline \multicolumn{6}{|l|}{${ }^{\mathrm{a}} p=0.013$} \\
\hline * Statistically significar & & & & & \\
\hline
\end{tabular}




\begin{tabular}{|c|c|c|c|c|}
\hline $\begin{array}{l}\text { Controls } \\
(n=25)\end{array}$ & $\begin{array}{l}\text { Group } 1 \\
(n=26)\end{array}$ & $\begin{array}{l}\text { Group } 2 \\
(n=25)\end{array}$ & $\begin{array}{l}\text { Group } 3 \\
(n=25)\end{array}$ & $P$ \\
\hline \multicolumn{5}{|c|}{$\begin{array}{l}\text { **The control group was not included in the statistical analyses when comparing antidiabetic drugs } \\
\text { between groups. }\end{array}$} \\
\hline \multicolumn{5}{|c|}{$\begin{array}{l}\text { F: Female, M: Male, BMI: Body Mass Index, SBP: Systolic Blood Pressure, DBP: Diastolic Blood } \\
\text { Pressure, }\end{array}$} \\
\hline \multicolumn{5}{|c|}{ HT: Hypertension, CAD: Coronary Artery Disease, PAD: Peripheral Artery Disease, CVD: Cerebrovascular } \\
\hline \multicolumn{5}{|c|}{$\begin{array}{l}\text { Disease, PD: Pulmonary Diseases, ACEi/ARB: Angiotensin-converting Enzyme Inhibitors/Angiotensin } \\
\text { Receptor }\end{array}$} \\
\hline \multicolumn{5}{|c|}{$\begin{array}{l}\text { Blockers, CCB: Calcium Canal Blockers, BB: Beta Blockers, ASA: Acetylsalicylic acid, SU: } \\
\text { Sulfonylureas, }\end{array}$} \\
\hline
\end{tabular}

Comparisons of biochemical data between the groups are given in Table 2. There was no statistically significant difference identified between the groups in terms of $\mathrm{Na}, \mathrm{K}, \mathrm{P}, \mathrm{uric}$ acid, T. Protein, T. Cholesterol, LDL-c, TG and CRP values ( $p>0.05$ ). HbA1c and blood glucose were identified to be statistically different between the group 1 and groups 2-3. GFR, BUN and Proteinuria were identified to be statistically different between the group 1 and groups 2-3. GFR and Proteinuria were also statistically significantly different between groups 2 and 3 . 
Table 2

Comparison of biochemical parameters between groups.

\begin{tabular}{|c|c|c|c|c|c|}
\hline & $\begin{array}{l}\text { Controls } \\
(n=25)\end{array}$ & $\begin{array}{l}\text { Group } 1 \\
(n=26)\end{array}$ & $\begin{array}{l}\text { Group } 2 \\
(n=25)\end{array}$ & $\begin{array}{l}\text { Group } 3 \\
(n=25)\end{array}$ & $P$ \\
\hline BUN (mg/dL) & $13(12-18)$ & $13(10-16)^{a}$ & $17(14-22)$ & $19(13-25)^{b}$ & 0.007 \\
\hline Creatinine (mg/dL) & $0.7(0.6-0.8)$ & $0.8(0.6-0.9)$ & $0.8(0.7-1.0)$ & $0.9(0.7-1.1)^{c}$ & 0.025 \\
\hline $\begin{array}{l}\text { GFR } \\
\left(\mathrm{mL} / \mathrm{min} / 1.73 \mathrm{~m}^{2}\right)\end{array}$ & 100(95-106) & $101(93-109)^{d}$ & $92(78-99)^{e}$ & $75(63-95)^{f}$ & $<0.001$ \\
\hline Sodium(mmol/L) & $\begin{array}{l}139(138- \\
141)\end{array}$ & 138(137-141) & $139(137-140)$ & $140(137-141)$ & 0.782 \\
\hline Potassium(mmol/L) & $4.5(4.4-5.0)$ & $4.6(4.3-4.6)$ & $4.5(4.4-5.0)$ & $4.6(4.3-5.1)$ & 0.936 \\
\hline Calcium (mg/dL) & 9.7(9.6-9.9) & 9.7(9.4-9.9) & 9.7(9.3-9.9) & $9.4(8.9-9.6)^{g}$ & 0.020 \\
\hline Phosphorus(mg/dL) & $3.5(3.2-3.9)$ & $3.8(3.5-3.9)$ & $3.7(3.2-4.1)$ & $3.8(3.4-4.2)$ & 0.277 \\
\hline Uric acid (mg/dL) & $5.6(4.4-6.1)$ & $4.9(4.2-5.8)$ & $4.8(4.1-5.7)$ & $5.2(4.2-6.2)$ & 0.345 \\
\hline T. Protein (g/dL) & 7.7(7.3-7.9) & 7.4(7.1-7.6) & 7.6(7.3-7.8) & 7.3(6.9-7.8) & 0.053 \\
\hline Albumin (g/dL) & $4.4(4.3-4.7)$ & $4.4(4.2-4.5)$ & $4.2(4.1-4.6)$ & $4.1(3.6-4.5)^{\mathrm{h}}$ & 0.035 \\
\hline T.Cholesterol (mg/dL) & $198 \pm 42$ & $203 \pm 43$ & $185 \pm 56$ & $206 \pm 40$ & 0.373 \\
\hline LDL-c (mg/dL) & $115 \pm 40$ & $120 \pm 34$ & $103 \pm 44$ & $124 \pm 32$ & 0.255 \\
\hline TG (mg/dL) & $\begin{array}{l}\text { 125(110- } \\
199)\end{array}$ & $177(123-257)$ & $127(92-219)$ & $167(124-223)$ & 0.124 \\
\hline HDL-c (mg/dL) & $54(49-59)$ & $46(40-53)^{\prime}$ & $49(41-64)$ & $47(42-51)^{j}$ & 0.036 \\
\hline $\begin{array}{l}\text { Blood Glucose } \\
\text { (mg/dL) }\end{array}$ & $95(85-99)$ & $\begin{array}{l}151(137- \\
170)^{\mathrm{k}}\end{array}$ & $\begin{array}{l}\text { 185(140- } \\
223)^{\prime}\end{array}$ & $\begin{array}{l}\text { 183(118- } \\
262)^{m}\end{array}$ & $<0.001$ \\
\hline
\end{tabular}

BUN: Blood Urea Nitrogen, GFR: Glomerular Filtration Rate, HDL-c: High Density Lipoprotein, LDL-C: Low Density Lipoprotein, TG: Triglyceride, CRP: C-Reactive Protein

a $p=0.006$ vs Group $2, p=0.008$ vs Group $3,{ }^{b} p=0.036$ vs Controls, ${ }^{c} p=0.010$ vs Controls, $p=0.013$ vs Group $1,{ }^{\mathrm{d}} p=0.020$ vs Group 2, ${ }^{\mathrm{e}} p=0.034$ vs Controls, ${ }^{\mathrm{f}} p<0.001$ vs Controls, ${ }^{\mathrm{g}} p=0.003$ vs Controls, $p=0.016$ vs Group $1,{ }^{\mathrm{h}} p=0.009$ vs Controls, ${ }^{\mathrm{p}} p=0.015$ vs Controls, ${ }^{\mathrm{j}} p=0.004$ vs Controls, ${ }^{\mathrm{k}} p<0.001$ vs Controls, $p=0.036$ vs Group 2, ${ }^{\mathrm{l}} p<0.001$ vs Controls, ${ }^{\mathrm{m}} p<0.001$ vs Controls, ${ }^{\mathrm{n}} p<0.001$ vs Controls, $p=0.025$ vs Group $2,{ }^{\circ} p<0.001$ vs Controls, ${ }^{\mathrm{P}} p<0.001$ vs Controls, ${ }^{\mathrm{r}} p=0.006$ vs Controls, $p=0.010$ vs Group $1,{ }^{\mathrm{s}} p=0.002$ vs Controls, $p=0.004$ vs Group $1, p=0.026$ vs Group $2,{ }^{\$} p<0.001$ vs Group $2, p<0.001$ vs Group $3,{ }^{\mathrm{t}} p<0.001$ vs Controls, ${ }^{\mathrm{u}} p<0.001$ vs Controls, ${ }^{\mathrm{u}} p<0.001$ vs Group $1, p=0.001$ vs Group 2, ${ }^{v} p=0.046$ vs Controls, ${ }^{y} p<0.001$ vs Controls, ${ }^{\mathrm{z}} p<0.001$ vs Controls, ${ }^{\mathrm{x}} p=0.005$ vs Controls, ${ }^{\mathrm{w}} p=0.004$ vs Controls, $p=0.019$ vs Group 1 


\begin{tabular}{|c|c|c|c|c|c|}
\hline & $\begin{array}{l}\text { Controls } \\
(n=25)\end{array}$ & $\begin{array}{l}\text { Group } 1 \\
(n=26)\end{array}$ & $\begin{array}{l}\text { Group } 2 \\
(n=25)\end{array}$ & $\begin{array}{l}\text { Group } 3 \\
(n=25)\end{array}$ & $P$ \\
\hline CRP (mg/dL) & $3.1(3.1-4.1)$ & $3.1(3.1-4.7)$ & $3.4(3.1-5.0)$ & $3.3(3.1-4.4)$ & 0.472 \\
\hline HbA1c (\%) & $5.4(5.3-5.7)$ & $7.5(6.7-8.3)^{n}$ & $8.2(7.5-9.2)^{\circ}$ & $8.4(7.3-9.3)^{p}$ & $<0.001$ \\
\hline Hemoglobin $(\mathrm{g} / \mathrm{dL})$ & $13.9 \pm 1.4$ & $13.8 \pm 1.5$ & $13.6 \pm 1.5$ & $12.5 \pm 1.4^{r}$ & 0.003 \\
\hline Hematocrit(\%) & $43.7 \pm 4.0$ & $43.4 \pm 4.3$ & $42.7 \pm 4.3$ & $39.2 \pm 4.2^{\mathrm{s}}$ & 0.001 \\
\hline Proteinuria(g/day) & $\begin{array}{l}0.080(0.040- \\
0.134)\end{array}$ & $\begin{array}{l}0.100(0.077- \\
0.149)^{\mathrm{s}}\end{array}$ & $\begin{array}{l}0.196(0.117- \\
0.455)^{\mathrm{t}}\end{array}$ & $\begin{array}{l}0.254(0.115- \\
1.085)^{\mathrm{u}}\end{array}$ & $<0.001$ \\
\hline $\begin{array}{l}\text { Serum mindin } \\
(\mathrm{ng} / \mathrm{mL})\end{array}$ & $\begin{array}{l}2.07(1.27- \\
2.73)\end{array}$ & $\begin{array}{l}2.14(1.89- \\
2.58)\end{array}$ & $\begin{array}{l}2.00(1.82- \\
2.39)\end{array}$ & $\begin{array}{l}1.66(1.52- \\
1.91)^{\ddot{u}}\end{array}$ & 0.001 \\
\hline $\begin{array}{l}\text { 24-hours urine mindin } \\
\text { (ng/day) }\end{array}$ & $\begin{array}{l}4740(3864- \\
7411)\end{array}$ & $\begin{array}{l}8300(4464- \\
11309)^{v}\end{array}$ & $\begin{array}{l}8998(7467- \\
13602)^{y}\end{array}$ & $\begin{array}{l}9047(6799- \\
11298)^{z}\end{array}$ & $<0.001$ \\
\hline \multicolumn{6}{|c|}{$\begin{array}{l}\text { BUN: Blood Urea Nitrogen, GFR: Glomerular Filtration Rate, HDL-c: High Density Lipoprotein, LDL-c: } \\
\text { Low Density Lipoprotein, TG: Triglyceride, CRP: C-Reactive Protein }\end{array}$} \\
\hline \multicolumn{6}{|c|}{ 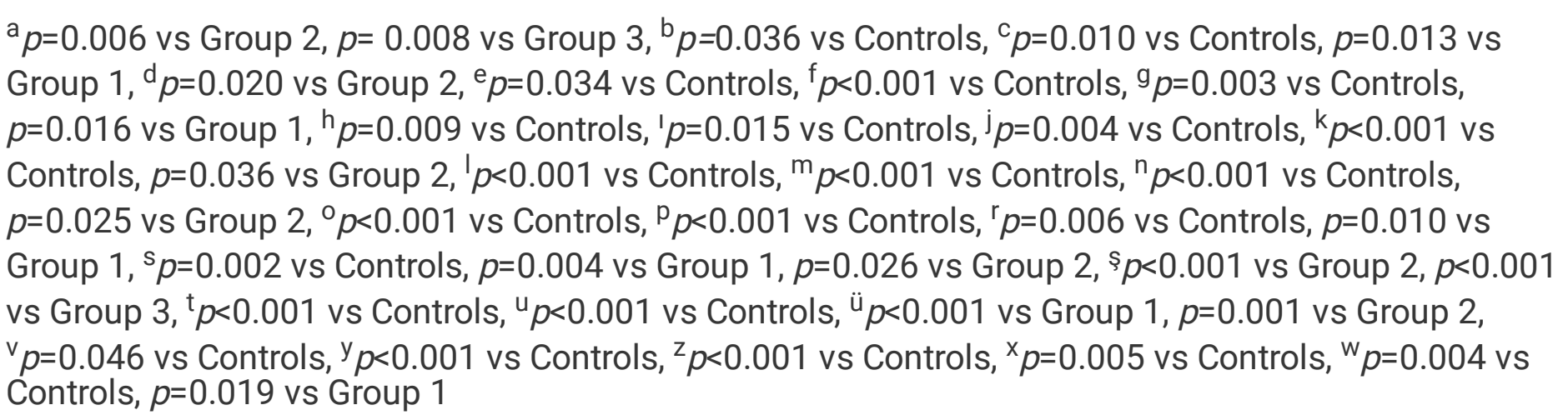 } \\
\hline
\end{tabular}

There were statistically significant differences between Group 3 and Groups 1-2 in terms of serum mindin levels (Table 2). Serum mindin levels were identified to be lower in Group 2 than group 1, however this difference was not statistically significant. There was no statistically difference between the control group and groups 1-2 (Figure 1).

There were statistically significant levels of difference identified between the control group and groups 12-3 in terms of 24-hours urine mindin levels (Table 2). The 24-hours urine mindin levels was higher in group 3 than group 1-2, however this difference was not statistically significant (Figure 2).

Correlation analysis was performed for serum mindin and 24-hours urine mindin (Table 3). There are negative correlation between serum mindin level and groups. Urine mindin levels over 24 hours were identified to be positively correlated with groups, $\mathrm{HbA1c}$, proteinuria, and the use of insulin, diuretic, BB, ASA and biguanide. There was no correlation identified between serum mindin and 24-hours urine mindin levels $(r=-0.130, P=0.195)$. 
Table 3

Correlation analysis results of serum mindin and 24-hours urine mindin.

\begin{tabular}{|c|c|c|c|c|c|}
\hline \multicolumn{2}{|l|}{ Serum Mindin } & \multicolumn{4}{|c|}{ 24-hours urine mindin } \\
\hline \multirow[t]{2}{*}{ Group } & $r=-0.269$ & Group & $r=0.376$ & Blood Glucose & $r=0.191$ \\
\hline & $P=0.007$ & & $P<0.001$ & & $P=0.055$ \\
\hline \multirow[t]{2}{*}{ Age } & $r=-0.235$ & Age & $r=0.085$ & Insulin & $r=0.220$ \\
\hline & $P=0.018$ & & $P=0.401$ & & $P=0.027$ \\
\hline \multirow[t]{2}{*}{ GFR } & $r=0.164$ & GFR & $r=-0.133$ & ACEi/ARB & $r=0.195$ \\
\hline & $P=0.101$ & & $P=0.186$ & & $P=0.051$ \\
\hline \multirow[t]{2}{*}{ Albumin } & $r=0.188$ & Albumin & $r=-0.035$ & Diuretics & $r=0.223$ \\
\hline & $P=0.060$ & & $P=0.732$ & & $P=0.025$ \\
\hline \multirow[t]{2}{*}{ HbA1c } & $r=-0.075$ & HbA1c & $r=0.247$ & BB & $r=0.200$ \\
\hline & $P=0.458$ & & $P=0.013$ & & $P=0.045$ \\
\hline \multirow[t]{2}{*}{ Proteinuria } & $r=-0.169$ & Proteinuria & $r=0.302$ & ASA & $r=0.246$ \\
\hline & $P=0.091$ & & $P=0.002$ & & $P=0.013$ \\
\hline \multirow[t]{2}{*}{ Hypertension } & $r=-0.196$ & Hypertension & $r=0.246$ & Biguanide & $r=0.226$ \\
\hline & $P=0.049$ & & $P=0.130$ & & $P=0.023$ \\
\hline
\end{tabular}

The study population was divided into two groups as those with retinopathy (Group 2 and Group 3) and those without retinopathy (Group 1). Multivariate regression analysis was performed for the main determinative parameters for retinopathy. Regression analysis results identified the main determinant of retinopathy was primarily $\mathrm{HbA} 1 \mathrm{c}$ level, with 24-hours urine mindin in 2nd place followed by proteinuria. Serum mindin level was not found to be significant for the prediction of retinopathy (Table 4). 
Table 4

Multivariate logistic regression analysis in patients with retinopathy and without retinopathy.

\begin{tabular}{|lllll|}
\hline Variables & \multicolumn{4}{c|}{ Multivariate Logistic Regression Analysis } \\
\cline { 2 - 6 } & B & Wald & OR (95\%Cl) & P \\
\hline Age & 0.076 & 2.255 & $1.079(0.977-1.193)$ & 0.133 \\
\hline GFR & -0.016 & 0.492 & $0.984(0.941-1.029)$ & 0.483 \\
\hline HbA1c & 0.579 & 7.400 & $1.785(1.176-2.710)$ & 0.007 \\
\hline Proteinuria & 9.769 & 5.544 & $17.485(5.140-59.486 .659)$ & 0.019 \\
\hline 24-Hours Urine Mindin & 0.000 & 6.494 & $1.000(1.000-1.000)$ & 0.011 \\
\hline Serum Mindin & 0.125 & 0.147 & $1.133(0.598-2.146)$ & 0.701 \\
\hline
\end{tabular}

GFR: Glomerular Filtration Rate

\section{Discussion}

In our study, 24-hours urine mindin levels were identified to be higher among patients with DM compared to a non-diabetic control group. Urine mindin levels were also found to increase in correlation with the severity of DR. There was a negative correlation between serum mindin level and retinopathy severity. Multivariate logistic regression analysis identified that 24-hour urine mindin level was the most important parameter for prediction of retinopathy after $\mathrm{HbA} 1 \mathrm{c}$.

Many factors play roles in the etiopathogenesis of DR. The most important mechanisms comprise oxidative stress [12] and inflammatory processes [13-19]. Inflammation and oxidative stress are very closely related. Inflammation may be assessed as tissue response to stress factors changing the hemostasis of oxidant tissues. Though oxidative stress and inflammatory pathways are described and therapeutic approaches affecting these pathways are determined and in spite of glycemic control blood pressure control and lipid-lowering treatments, the prevalence of DR is increasing. In spite of control of risk factors known for many diseases, retinopathy progression continues in patients. This situation leads to the consideration that other molecules may play a role in the pathogenesis.

Mindin was shown to be an important molecule in construction of inflammatory cytokines like TNF-alpha and IL-6 [20]. For migration of leukocytes to the inflammation area, mutual interaction between many integrins on leukocytes and ligands on endothelial cells is required. Mindin is a new ligand for integrins that has been shown to have critical importance for migration of inflammatory cells [9]. Mindin may be target molecule for many diseases. A study administering rats $3 \%$ dextran sulfate sodium to induce an acute colitis model have shown mindin increased the acute colitis model and stimulated NF-k B promotor 
activation via TLR-9. Rats with induced defective mindin were identified to have serious defects in immune response formation properties [21]. This situation reveals the role of mindin as a basic element of innate and adaptive immunity. Previous studies have shown the correlation between urine mindin levels and DN. Murakoshi et al. [10] in a study of rats with type 2 DM found podocyte injury was more intense in the high-calorie group and that urine mindin levels may be a marker of podocyte injury identified in urine before albumin/creatinine ratio. Another study by Kahvecioglu et al [22] have identified that serum mindin levels increased in DN patients in parallel with proteinuria levels. In this study, serum mindin levels increased in parallel with the loss of renal function. In our study, mindin was measured in both 24-hours urine and serum, as previous studies have emphasized that measurement of urine levels may be more significant [10]. In our study, no statistically significant correlation was identified between serum and urine mindin levels. While urine mindin level was correlated with presence and severity of retinopathy, serum mindin level was identified to have a negative correlation with severity of retinopathy showing there may be different factors affecting mindin fractionation. At the same time, we identified a significant positive correlation between urine mindin level and $\mathrm{HbA1c}$ levels in DM patients. Regression analysis for retinopathy performed in our study identified $\mathrm{HbA} 1 \mathrm{c}$, proteinuria and urine mindin levels as independent variables.

There is a very close correlation between microalbuminuria and DR in type 2 DM patients. Rani et al have found that the prevalence of DR in patients with microalbuminuria is doubled while it is six times for those with macroalbuminuria [23]. In our study, proteinuria was identified to be significantly high in the DR patient group compared to those without DR and the control group. Logistic regression analysis identified proteinuria as an independent risk factor for retinopathy. A recent study assessed mindin as an early marker of glomerular basal membrane injury [24]. Mindin causes cell/matric adhesion in glomeruli and changes in the glomerular filtration barrier with its role in inflammation (10). Finally, podocyte cell loss and glomerulosclerosis cause proteinuria. In our study, in accordance with the literature, there was a significant correlation identified between proteinuria and urine mindin. This indicates that identification of increased mindin, with elevation identifiable in the early period of the underlying pathogenetic process for diabetic nephropathy, in 24-hours urine may be assessed as an early biomarker with stimulating properties for retinopathy, just as for nephropathy.

There are a range of limitations of our study. First, our study population was taken from a single center and comprises relatively low numbers of patients. Additionally, the mean age of our control group did not match the diabetic patient group, which is another limitation of the study.

In conclusion, urine mindin levels increase in parallel with the severity of DR. 24 hour urine mindin level may be assessed as an independent variable for the determination of DR. Additionally, 24-hours urine mindin levels are also correlated with proteinuria, a finding in diabetic nephropathy. Serum mindin levels were not correlated with 24-hours urine mindin levels. Additionally, the positive correlation between DR with $\mathrm{HbA} 1 \mathrm{c}$ and proteinuria once more emphasizes the effect of these two factors in development of DR and the importance of strict diabetes regulation for the prevention of DR. 
With the property of being the first in this field to assess DR with urine and serum mindin levels, there is a need for experimental studies researching pathways associated with mindin in diabetic retinopathy pathogenesis as a continuation of our study.

\section{Declarations}

Financial interest

The author(s) have no financial interests to disclose.

\section{Conflict of interest}

None of the authors have any conflicts of interest related to declare that are relevant to the content of this article

\section{Ethical standards}

This study was performed in line with the principles of the Declaration of Helsinki. Approval was granted by the Ethics Committee of Hitit University (06.01.2017/2016.52). Informed consent was obtained from all individual participants included in the study.

\section{References}

1. Lee R, Wong TY, Sabanayagam C (2015) Epidemiology of diabetic retinopathy, diabetic macular edema and related vision loss. Eye Vis (Lond) 2:17. doi:10.1186/s40662-015-0026-2

2. Caglar C, Demir E, Kucukler K, Durmus M (2016) A Bibliometric Analysis of Academic Publication on Diabetic Retinopathy Disease Trends During 1980-2014; a Global and Medical View. Int J Ophthalmol 9(11):1663-1668. doi:10.18240/ijo.2016.11.21

3. Spijkerman AM, Dekker JM, Nijpels G et al (2003) Microvascular complications at time of diagnosis of type 2 diabetes are similar among diabetic patients detected by targeted screening and patients newly diagnosed in general practice: the hoorn screening study. Diabetes Care 26:2604-2608. doi.org/10.2337/diacare.26.9.2604

4. Atchison E, Barkmeier A. The role of systemic risk factors in diabetic retinopathy. Curr Ophthalmol Rep 2016:4:84-89. doi: 10.1007/s40135-016-0098-8

5. Dalla VM, Masiero A, Roiter AM, Saller A, Crepaldi G, Fioretto P (2003) Is podocyte injury relevant in diabetic nephropathy? Studies in patients with type 2 diabetes. Diabetes 52:1031-1035. doi:10.2337/diabetes.52.4.1031

6. Romero AP, Sagarra AR, Baget BM, Fernandez BJ, Marin IM (2010) Prevalence and relationship between diabetic retinopathy and nephropathy, and its risk factors in the north-east of Spain, a population-based study. Ophthalmic Epidemiol 17(4):251-265. doi:10.3109/09286586.2010.498661 
7. Wolf G, Müller N, Mandecka A, Müller UA (2007) Association of diabetic retinopathy and renal function in patients with types 1 and 2 diabetes mellitus. Clin Nephrol 68(2):81-86. doi:10.5414/cnp68081

8. Atchison E, Barkmeier A (2016) The role of systemic risk factors in diabetic retinopathy. Curr Ophthalmol Rep 4:84-89. doi:10.1007/s40135-016-0098-8

9. Jia W, Li H, He YW (2005) The extracellular matrix protein mindin serves as an integrin ligand and is critical for inflammatory cell recruitment. Blood 106:3854-3859. doi:10.1182/blood-2005-04-1658

10. Murakoshi M, Tanimoto M, Gohda T, Takagi SHM, Horikoshi S, Tomino Y (2011) Mindin: a novel marker for podocyte injury in diabetic nephropathy. Nephrol Dial Transplant 26:2153-2160. doi:10.1093/ndt/gfq708

11. Grading diabetic retinopathy (1991) from stereoscopic color fundus photographs--an extension of the modified Airlie House classification. ETDRS report number 10. Early Treatment Diabetic Retinopathy Study Research Group. Ophthalmology 98:786-806. doi.org/10.1016/S01616420(13)38012-9

12. Wu Y, Tang L, Chen B (2014) Oxidative stress: implications for the development of diabetic retinopathy and antioxidant therapeutic perspectives. Oxid Med Cell Longev 2014:752387. doi:10.1155/2014/752387

13. Semeraro F, Cancarini A, Dell'Omo R, Rezzola S, Romano MR, Costagliola C (2015) Diabetic retinopathy: vascular and inflammatory disease. J Diabetes Res 2015:582060. doi:10.1155/2015/582060

14. Haskins K, Bradley B, Powers K et al (2003) Oxidative stress in type 1 diabetes. Ann N Y Acad Sci 1005:43-54. doi.org/10.1196/annals. 1288.006

15. Romeo G, Liu WH, Asnaghi V, Kern TS, Lorenzi M (2002) Activation of nuclear factor-kappaB induced by diabetes and high glucose regulates a proapoptotic program in retinal pericytes. Diabetes 51:2241-2248. doi.org/10.2337/diabetes.51.7.2241

16. Du XL, Edelstein D, Rossetti L, Fantus IG, Goldberg H, Ziyadeh F, Wu J, Brownlee M (2000) Hyperglycemia induced mitochondrial superoxide overproduction activates the hexosamine pathway and induces plasminogen activator inhibitor-1 expression by increasing Sp1 glycosylation. Proc Natl Acad Sci U S A 97:12222-12226. doi.org/10.1073/pnas.97.22.12222

17. Jialal I, Kaur H (2012) The role of Toll-like receptors in diabetes-induced inflammation: implications for vascular complications. Curr Diab Rep 12:172-179. doi:10.1007/s11892-012-0258-7

18. Rivera JC, Dabouz R, Noueihed B, Omri S, Tahiri H, Chemtob S (2017) Ischemic Retinopathies: Oxidative Stress and Inflammation. Oxid Med Cell Longev 2017:3940241. doi:10.1155/2017/3940241

19. Joussen AM, Poulaki V, Mitsiades N, Kirchhof B, Koizumi K, Döhmen S, Adamis AP (2002) Nonsteroidal anti-inflammatory drugs prevent early diabetic retinopathy via TNF-a suppression. FASEB J 16(3):438-440. doi.org/10.1096/fj.01-0707fje 
20. He YW, Li H, Zhang J, Hsu CL, Lin E, Zhang N, Guo J, Forbush KA, Bevan MJ (2004) The extracellular matrix protein mindin is a pattern-recognition molecule for microbial pathogens. Nat Immunol 5:8897. doi.org/10.1038/ni1021

21. Guleng B, Ya-Mei L, Lin Ren J (2010) Mindin is upregulated during colitis and may activate NF-jB in a TLR-9 mediated manner. World J Gastroenterol 16:1070-1075. doi:10.3748/wjg.v16.i9.1070

22. Kahvecioglu S, Guclu M, Ustundag Y, Gul CB, Dogan I, Dagel T et al (2015) Evaluation of serum spondin 2 levels in the different stages of type 2 diabetic nephropathy. Nephrology (Carlton) 20:721726. doi:10.1111/nep.12507

23. Rani PK, Raman R, Gupta A, Kulothungan V, Sharma T (2011) Albuminuria and Diabetic Retinopathy in Type 2 Diabetes Mellitus Sankara Nethralaya Diabetic Reti- nopathy Epidemiology And Molecular Genetic Study (SN-DREAMS, report 12). Diabetol Metab Syndr 3:9. doi:10.1186/1758-5996-3-9

24. Naudin C, Smith B, Bond DR, Dun MD, Scott RJ, Ashman LK (2017) Characterization of the early molecular changes in the glomeruli of Cd151 mice highlights induction of mindin and MMP-10. Sci Rep 7:15987. doi:10.1038/s41598-017-15993-3

\section{Figures}

\section{Serum mindin $(\mathrm{ng} / \mathrm{mL})$}

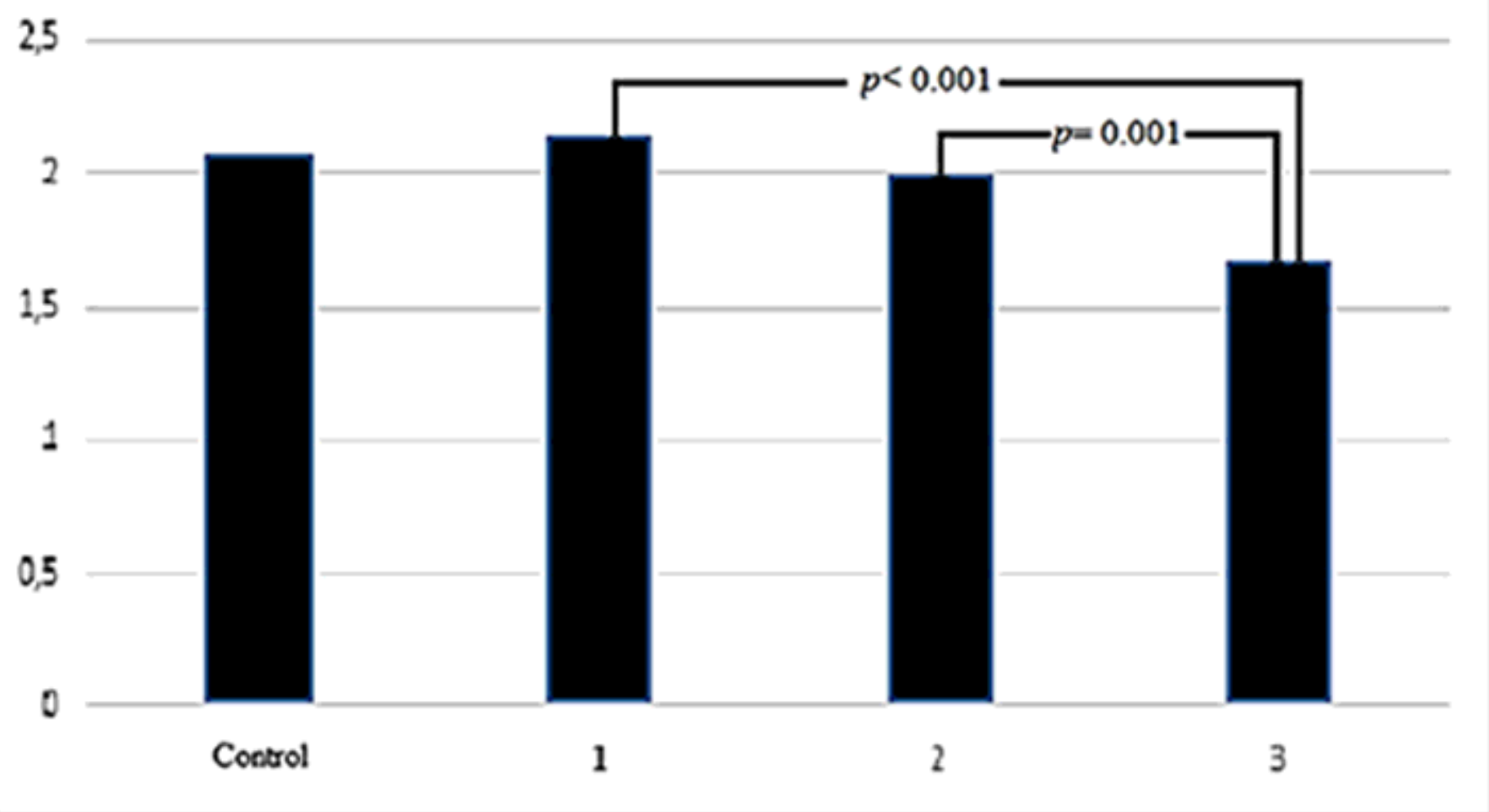

Figure 1 


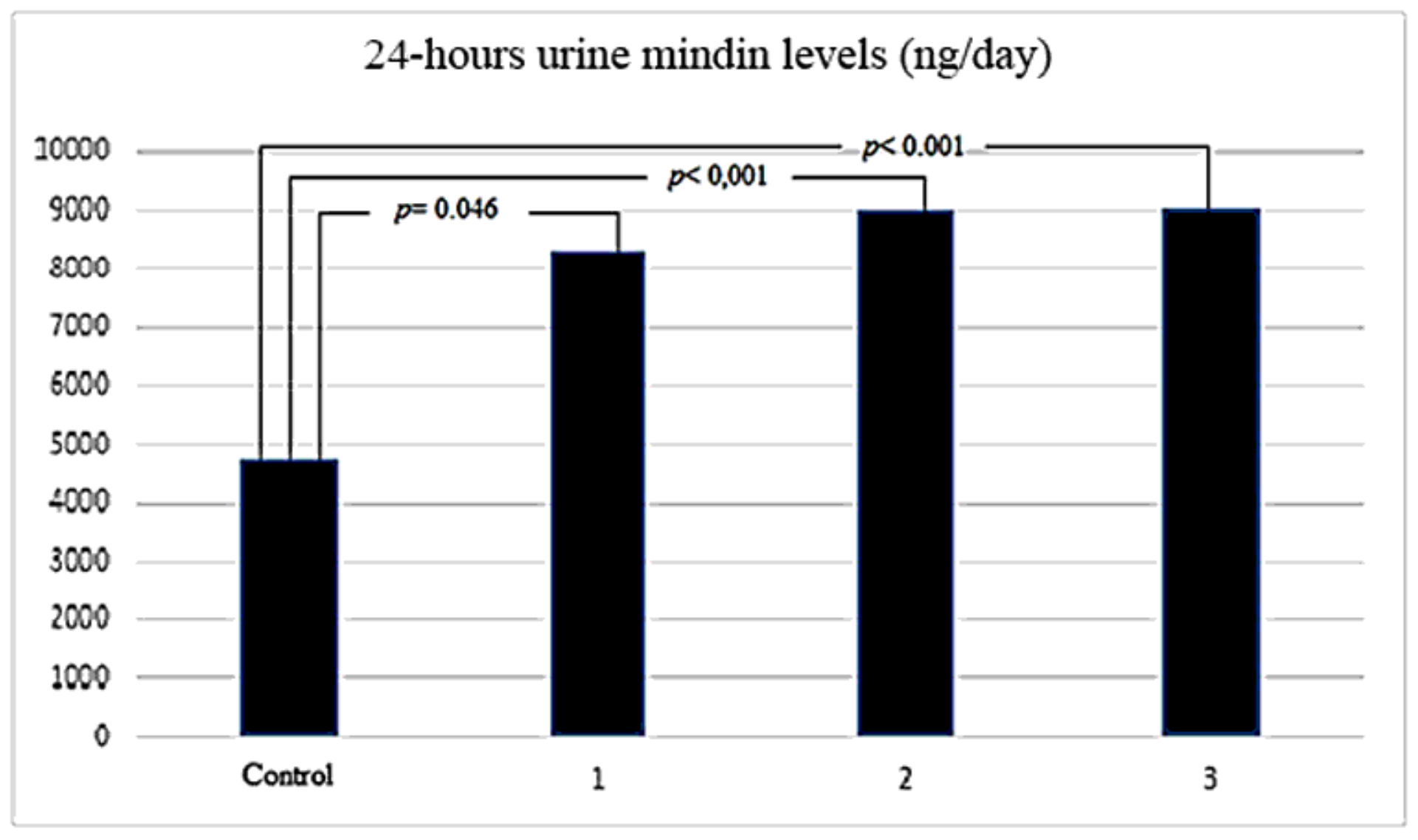

Figure 2

Comparison of 24-hours urine mindin levels between groups 